\title{
HUBUNGAN SIFAT FISIK DAN KIMIA TANAH DENGAN PERTUMBUHAN MERANTI MERAH DI KHDTK HAURBENTES
}

\section{Correlation Between Physical and Chemical Soil Properties and Growth of Red Meranti in Haurbentes Forest Research}

\author{
Exze Erizilina $^{\mathrm{a}}$, Prijanto Pamoengkas ${ }^{\mathrm{b}}$, dan Darwo $^{\mathrm{c}}$ \\ a Program Studi Silvikultur Tropika, Sekolah Pascasarjana IPB, Kampus IPB Darmaga, Bogor 16680 - \\ exzeerizilina@gmail.com \\ ${ }^{b}$ Departemen Silvikultur, Fakultas Kehutanan, Institut Pertanian Bogor, Kampus IPB Darmaga, Bogor 16680 \\ ' Pusat Litbang Hutan Tanaman, Jl. Gunung Batu No.5, Bogor 16610
}

\begin{abstract}
Failure in degraded forest rehabilitation was caused by using selected species without sufficient attention on site characterictics. Species selection by looking at site limiting factor, will increase success in degraded forest rehabilitation. The objective of this reasearch was to study the influence of physical and chemical soil properties on growth of Shorea leprosula Miq, Shorea palembanica Miq, dan Shorea mecisopteryx. Data were analyzed using multiple linear regression analysis with mean annual increment (MAI) of height and diameter as dependent variable and soil properties as independent variable. The results showed that growth increment of S.palembanica was influnced by soil perperties with $R^{2}$ adjusted value for MAI-diameter and MAI-height repectively, 0.946 and 0.674 whereas others two Shorea have $R^{2}$ adjusted value $<0.5$. The research also showed that available P content was the limiting factor of the three species. There was a difference of each species in respond to the available $P$ content. MAI-height on S. mecisopteryx and MAI-diameter and MAI-height on S. pelambanica will increase in line with decreasing available $P$ content while $S$. leprosula required $P$ available increasing in order to increase of MAI-diameter. This indicates that each species have specific response on certain soil properties content.
\end{abstract}

Keywords: Growth, haurbentes, red meranti, soil properties, species selection.

(Diterima: 15-08-2017; Disetujui: 16-11-2017)

\section{Pendahuluan}

Deforestrasi dan degradasi hutan merupakan penyebab utama berkurangnya hutan yang ada di Indonesia. KLHK (2014) melaporkan bahwa laju deforestrasi pada tahun 2013-2014, untuk hutan primer adalah sebesar 429.400 ha/tahun dan hutan sekunder sebesar 25,725 ha/tahun. Bila dibandingkan dengan tahun sebelumnya (2012-2013) laju deforestrasi terus meningkat, yaitu sebelumnya 19,035 ha/tahun (hutan primer) dan 358,887 ha/tahun (hutan sekunder). Peningkatan laju deforestrasi ini menyebabkan terbentuknya hutan yang tidak produktif dan mengancam keberadaan beberapa jenis dari famili Dipterocaraceae.

Permasalahan deforestrasi, diantaranya dapat diatasi dengan melakukan rehabilitasi hutan yaitu upaya mengembalikan, mempertahankan dan meningkatkan produktivitas hutan. Salah satu faktor penting agar kegiatan tersebut berhasil yaitu pemilihan jenis yang sesuai dengan kondisi tempat tumbuh. Beberapa penelitian menyarankan untuk menggunakan jenisjenis lokal selain jenis cepat tumbuh seperti jenis-jenis dari Dipterocarpaceae untuk kegiatan rehabilitasi (Appanah dan Weinland, 1996; Nussbaum dan Hoe, 1996; Otsamo et al., 1996; Hamzah et al., 2009; Sovu et al., 2009; Scheneider, 2013; Subiakto et al., 2016;
Kok Loong Yeong et al., 2016). Dari 10 marga dari famili Dipterocarpaceae, kelompok Shorea merupakan kelompok marga terbesar dan terpenting yang tersebar di Indonesia untuk ditingkatkan populasi dan potensi tegakannya. Dari marga Shorea ada tiga spesies yang sedang diteliti di hutan tidak produktif yaitu Shorea leprosula, Shorea mecisopteryx dan Shorea palembanica tergolong dalam kelompok meranti merah. S. leprosula (meranti tembaga) dapat tumbuh dengan baik pada tanah yang berdrainase baik maupun tanah rawa pada kondisi tanah liat (Soerianegara dan Lemmens, 1994). Jenis shorea ini yang paling sering dikembangkan karena tumbuh lebih cepat dibandingkan dengan jenis tanaman Dipterocarpaceae lainnya. Dilain pihak, $S$. palembanica dan $S$. mecisopteryx merupakan jenis-jenis yang belum banyak diteliti ataupun dikembangkan. S. mecisopteryx umumnya tumbuh pada kondisi tanah yang liat berpasir (sandy clay). S. palembanica umumnya banyak ditemukan di sepanjang tepi sungai dan di rawa air tawar pada ketinggian yang rendah (Soerianegara dan Lemmens, 1994).

Beberapa penelitian menunjukkan bahwa pertumbuhan bervariasi walaupun spesies yang digunakan sama pada masing-masing tempat tumbuh. Untuk pertumbuhan S. leprosula, Hamzah et al. (2009) melaporkan bahwa riap diamater pada umur 6 tahun 
sebesar $1.10 \mathrm{~cm} /$ tahun dan Affendy et al. (2009) juga melaporkan pertumbuhan diamater $S$. leprosula pada umur 9 tahun sebesar $1.03 \mathrm{~cm} /$ tahun. Penelitian Widiyatno et al. (2014) melaporkan bahwa S. leprosula pada umur 6.5 tahun memiliki riap diameter sebesar $2.20 \mathrm{~cm} /$ tahun. Menurut Soekotjo (1993) dalam Wahyudi (2011) riap tegakan bersifat spesifik untuk setiap tempat tumbuh sehingga tidak dapat digunakan untuk memprediksi riap tanaman sejenis pada tempat yang berbeda. Dalam rangka mendukung pemilihan jenis yang sesuai dengan tempat tumbuhnya, diperlukan uji jenis guna memperoleh faktor-faktor yang memengaruhi pertumbuhan tanaman di areal yang diujikan. Tanah sebagai tempat tumbuh tanaman, merupakan salah dapat mempengaruhi pertumbuhan tanaman baik sifat fisik dan kimianya. Penelitian ini bertujuan untuk mengetahui hubungan pertumbuhan 3 jenis shorea ( $S$. leprosula, $S$. palembanica, dan $S$. mecisopteryx) terhadap beberapa sifat fisik dan kimia tanah.

\section{Metode}

\subsection{Lokasi dan Waktu Penelitian}

Kegiatan penelitian ini dilakukan di Hutan Penelitian Haurbentes, Jasinga, Bogor. Kawasan hutan dengan tujuan khusus (KHDTK) Haurbentes secara administrasi pemerintahan termasuk ke kampung Haurbentes, Desa Jugala Jaya dan Desa Wirajaya, Kecamatan jasinga, Kabupaten Bogor. Luas KHDTK Haurbentes keseluruhan sebesar 105.5 ha. KHDTK Haurbentes terletak pada ketinggian \pm 250 meter di atas permukaan laut (dpl) dan secara geografis terletak pada $6^{\circ} 32^{\prime}-6^{\circ} 33 \mathrm{LS}$ dan $106^{\circ} 26$ BT. Tipe curah hujan daerah KHDTK Haurbentes berdasarkan klasifikasi Schmidt dan Ferguson adalah tipe A dan termasuk dalam kategori iklim basah dengan curah hujan rata-rata 4267 $\mathrm{mm} /$ tahun. Keadaan topografi di areal KHDTK Haurbentes berbukit-bukit dengan lereng agak curam sampai curam yang mengarah ke Utara, dengan kemiringan lereng $>16 \%$. Jenis tanah di KHDTK Haurbentes terdiri dari tiga jenis tanah yaitu Podsolik Merah Kuning, Regosol, dan Brown Forest Soil (Pusat penelitian dan Pengembangan Hutan dan Konservasi Alam 2005).

Plot penelitian dibangun pada petak seluas 0.525 ha. Pengambilan data dilakukan mulai Maret sampai Mei 2017. Layout penanaman disajikan pada Gambar 1. Analisa sifat fisik tanah dilakukan di Laboratorium Tanah dan Kesuburan Tanah, Depertemen Tanah dan Sumberdaya Lahan, Fakultas Pertanian IPB sedangkan analisa sifat kimia tanah dilakukan di Laboratorium Tanah SEAMEO Biotrop.

\subsection{Pengambilan Data}

Pengambilan data dilakukan saat tanaman berumur 3.5 tahun. Pengukuran ini dilakukan pada ketiga jenis tanaman yang disebut di atas. Tanaman diukur diameter dan tinggi tanamannya, selanjutnya dihitung rata-rata diameter dan tinggi tiap plot jenis. Data pertumbuhan yang digunakan dalam analisis regresi berganda, diambil sampel sebanyak 9 sampel tanaman tiap jenisnya sehingga total tanaman yang digunakan 27 tanaman.
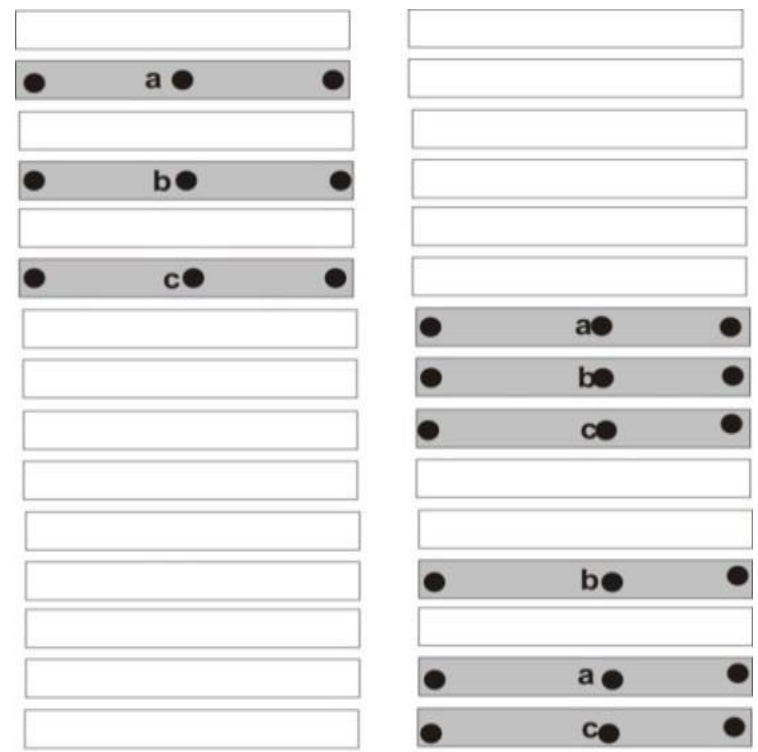

Keterangan :

a: Shorea leprosula Miq.

b: Shorea mecisopteryx Miq.

c: Shorea palembanica Ridl.

Titik pengambilan contoh tanah

Gambar 1. Layout tanaman

Pengambilan sampel tanah dilakukan pada kedalaman 0-20 cm dari permukaan tanah. Setiap satuan sampel tanah yang diambil berupa sampel tanah terganggu dengan menggunakan bor tanah dan sampel tanah utuh dengan mengggunakan ring sampel. Contoh tanah utuh (tidak terganggu) dan contoh tanah terganggu diambil sebanyak 3 titik pada setiap plot sehingga masing-masing jenis tanaman memiliki 9 contoh tanah. Total sampel tanah sebanyak 27 sampel. Contoh tanah utuh dalam ring sampel digunakan untuk analisis bulk density dan porositas. Contoh tanah terganggu untuk analisis sifat fisik tanah lainnya seperti tekstur tanah (persentase pasir, debu, liat), dan kimia tanah seperti C-organik dan N-total, dan Ptersedia.

\subsection{Analisis data}

Analisis data pertumbuhan diameter dan tinggi dilakukan dengan menghitung riap diameter dan tinggi rata-rata (MAI). Perhitungan riap diameter dan tinggi rata-rata (MAI) didasarkan pada rumus:

$$
I d=\frac{d i}{t i} \text { dan } I h=\frac{h i}{t i}
$$

dimana:

$I=$ Riap diameter rata-rata tahunan jenis ke-i (cm/tahun).

$d i=$ Rata - rata diameter tanaman jenis ke-i $(\mathrm{cm})$

hi $=$ Rata-rata tinggi tanaman jenis ke-i $(\mathrm{cm})$

$t i=$ Umur tanaman jenis ke-i (tahun). 
Analisis regresi linier berganda ditujukan untuk mengidentifikasi sifat-sifat tanah yang paling erat hubungannya dengan pertumbuhan ketiga jenis Shorea tersebut, serta mencari pola hubungan matematik antara peubah sifat-sifat tanah tersebut dengan peubah pertumbuhan tanaman (diameter dan tinggi tanaman). Peubah sifat-sifat tanah mulanya ada sebanyak 8 peubah yaitu C-organik, N-total, P-tersedia, bulk density, porositas, pasir, debu dan liat. Delapan peubah tersebut kemudian diuji multikolinearitas. Selanjutnya jika tidak terjadi mulltikolineritas maka diteruskan analisis regresi bertatar (stepwise) yang ditujukan untuk menghindari terjadinya kolineritas dalam regresi.

$$
\mathrm{Y}=\mathrm{b}_{0}+\mathrm{b}_{1} \mathrm{X}_{1}+\mathrm{b}_{2} \mathrm{X}_{2}+\ldots \ldots \ldots .+\mathrm{b}_{9} \mathrm{X}_{8}+\varepsilon
$$

dimana:

$$
\begin{array}{ll}
\mathrm{Y} & =\begin{array}{r}
\text { Rata-rata riap diameter setinggi } \\
\text { dada/tinggi tanaman }(\mathrm{m})
\end{array} \\
\mathrm{X}_{1}, \mathrm{X}_{2}, \ldots, \mathrm{X}_{8} & =\text { Sifat-sifat tanah } \\
\mathrm{b}_{0}, \mathrm{~b}_{1}, \ldots, \mathrm{b}_{9} & =\text { Konstant } \\
\varepsilon & =\text { Sisaan }
\end{array}
$$

Sifat-sifat tanah yang dipilih dalam penelitian ini adalah sebagai berikut $\mathrm{C}$-organik tanah $\left(\mathrm{X}_{1}\right), \mathrm{N}$-total $\left(\mathrm{X}_{2}\right)$ P-tersedia $\left(\mathrm{X}_{3}\right)$, bulk density $\left(\mathrm{X}_{4}\right)$, porositas $\left(\mathrm{X}_{5}\right)$, pasir $\left(\mathrm{X}_{6}\right)$, debu $\left(\mathrm{X}_{7}\right)$ dan liat $\left(\mathrm{X}_{8}\right)$. Seleksi peubahpeubah bebas yang memberikan sumbangan nyata dalam menerangkan keragaman pertumbuhan Dipterocarpaceae digunakan metode Stepwise dengan program SPSS. Pengujian model dilakukan dengan menggunakan analisis sidik ragam (ANOVA). Analisis ragam untuk menguji hipotesis $\mathrm{Ho}: \beta 1=0$. Hipotesis nol akan diterima bila F-hitung $\geq \mathrm{T}$-tabel. Keterandalan dari model yang diperoleh dapat dilihat dari kemampuan model menerangkan keragaman nilai peubah Y. Ukuran ini sering disebut koefisien determinasi $\left(\mathrm{R}^{2}\right)$. Semakin besar $\mathrm{R}^{2}$ berarti model semakin mampu menerangkan perilaku peubah $\mathrm{Y}$. Kisaran nilai $\mathrm{R}^{2}$ mulai dari $0 \%$ sampai $100 \%$.

\section{Hasil dan Pembahasan}

\begin{tabular}{|c|c|c|c|c|c|c|}
\hline Jenis Tanaman & Peubah bebas & Nilai & $\begin{array}{l}\text { Rata-rata Riap Diameter } \\
(\mathrm{cm} / \mathrm{th})\end{array}$ & $\begin{array}{l}\text { Rata-rata } \\
(\mathrm{m} / \mathrm{th})\end{array}$ & Riap & Tinggi \\
\hline \multirow{9}{*}{ Shorea leprosula } & $\mathrm{C}$ organic & 2.9 (sedang) -3.09 (tinggi) $\%$ & \multirow{9}{*}{1.4643} & \multirow{9}{*}{0.70} & & \\
\hline & $\mathrm{N}$ total & 0.2 (rendah) -0.27 (sedang) $\%$ & & & & \\
\hline & $\mathrm{P}$ tersedia & 9.1 (sedang) - 14.2 (tinggi) $\mathrm{ppm}$ & & & & \\
\hline & Pasir & $19.8-27.4 \%$ & & & & \\
\hline & Debu & $19.3-33.4 \%$ & & & & \\
\hline & Liat & $46.5-55.2 \%$ & & & & \\
\hline & Tekstur & Liat & & & & \\
\hline & Porositas & $64.03-71.97 \%$ & & & & \\
\hline & Bulkdensity & $0.74-1.03\left(\mathrm{~g} / \mathrm{cm}^{3}\right)$ & & & & \\
\hline \multirow{9}{*}{$\begin{array}{l}\text { Shorea } \\
\text { mecisopteryx }\end{array}$} & C organic & 1.92 (rendah)- 2.74 (sedang) \% & \multirow{9}{*}{0.8225} & \multirow{9}{*}{0.72} & & \\
\hline & $\mathrm{N}$ total & 0.17 (rendah)- 0.26 (sedang) $\%$ & & & & \\
\hline & $\mathrm{P}$ tersedia & 8.2 (sedang)-14.6 (sedang) ppm & & & & \\
\hline & Pasir & $19.4-27.3 \%$ & & & & \\
\hline & Debu & $23.1-31.6 \%$ & & & & \\
\hline & Liat & $46.8-58.6 \%$ & & & & \\
\hline & Tekstur & Liat & & & & \\
\hline & Porositas & $55.3-83.19 \%$ & & & & \\
\hline & Bulkdensity & $0.45-1.18\left(\mathrm{~g} / \mathrm{cm}^{3}\right)$ & & & & \\
\hline \multirow{9}{*}{$\begin{array}{l}\text { Shorea } \\
\text { palembanica }\end{array}$} & C organic & 1.48 (rendah)-2.31 (sedang) $\%$ & \multirow{9}{*}{0.9476} & \multirow{9}{*}{0.92} & & \\
\hline & $\mathrm{N}$ total & 0.12 (rendah)- 0.23 (sedang) $\%$ & & & & \\
\hline & $\mathrm{P}$ tersedia & 8.2 (sedang)-11.3 (sedang) ppm & & & & \\
\hline & Pasir & $15.3-24.2 \%$ & & & & \\
\hline & Debu & $19.5-33.4 \%$ & & & & \\
\hline & Liat & $48.3-52.6 \%$ & & & & \\
\hline & Tekstur & Liat & & & & \\
\hline & Porositas & $51.94-70.17 \%$ & & & & \\
\hline & Bulkdensity & $0.79-1.27\left(\mathrm{~g} / \mathrm{cm}^{3}\right)$ & & & & \\
\hline
\end{tabular}

\subsection{Kondisi Tempat Tumbuh}

Secara keseluruhan kondisi tempat tumbuh ketiga jenis Shorea hampir sama seperti yang disajikan pada Tabel 1.

Tabel 1. Karakteristik sifat tanah pada ketiga tempat tumbuh

Kadar sifat kimia tanah pada jenis S. palembanica dan S. mecisopteryx hampir sama dengan kadar Corganik dan $\mathrm{N}$ total yang tergolong rendah sampai sedang, dan kadar P-tersedia yang tergolong sedang. Pada jenis S.leprosula memiliki kadar C-organik yang lebih tinggi yaitu berkisar pada 2.9 - 3.09 yang tergolong sedang sampai tinggi. $\mathrm{N}$ total tanah pada jenis ini tergolong rendah hingga sedang dan P-tersedia yang tergolong sedang hingga tinggi. Untuk sifat fisik tanah dari ketiga jenis tanaman menunjukkan nilai yang hampir sama dengan tekstur tanah yang tergolong liat 
dengan kadar liat lebih dari 50\% dan nilai porositas dan bulk density yang tidak jauh berbeda.

S. leprosula dan S. mecisopteryx pada umumnya dapat tumbuh dengan baik pada kondisi tanah yang mengandung liat yang cukup tinggi. Hal ini diduga yang mengakibatkan kedua jenis ini dapat beradaptasi dan tumbuh dengan baik pada lokasi tempat tumbuh. $S$. palembanica umumnya banyak ditemukan di sepanjang tepi sungai dan di rawa air tawar pada ketinggian yang rendah. Pada lokasi penelitian terdapat anak sungai yang melintasi plot penelitian, hal ini diduga yang membuat jenis ini dapat tumbuh dengan baik. Ketercukupan pasokan air akan mendukung pertumbuhan tanaman. Sehingga

dapat terlihat bahwa kondisi tempat tumbuh (sifat-fisik dan kimia tanah) mendukung pertumbuhan ketiga jenis Shorea ini.

\subsection{Hubungan antar peubah bebas (sifat kimia dan fisik tanah)}

Hubungan antar peubah bebas disajikan dalam Tabel 2. Pengujian hubungan ini dilakukan untuk menyeleksi peubah yang dapat dipakai dalam regresi linier berganda. Dari 8 peubah bebas yang diukur, beberapa peubah bebas memiliki keeratan hubungan (koefisien korelasi) yang tinggi $(\geq 0.7)$.

Tabel 2. Pasangan peubah bebas yang mempunyai koefesian korelasi

\begin{tabular}{ccc}
\hline Jenis Tanaman & Pasangan Peubah Bebas & $\begin{array}{c}\text { Koefisien } \\
\text { Korelasi }\end{array}$ \\
\hline \multirow{4}{*}{ S. leprosula } & C-organik dan N total & 0.842 \\
& Pasir dan Debu & -0.666 \\
& Debu dan Liat & -0.729 \\
& Porositas dan Bulk & -0.999 \\
density & \\
\hline S. mecisopteryx & C-organik dan N total & 0.839 \\
& Pasir dan debu & -0.827 \\
& Porositas dan Bulk & -1 \\
\hline density & 0.943 \\
S. & C-organik dan N total & -0.859 \\
& Pasir dan Debu & -0.831 \\
& Debu dan Liat & -1 \\
& Porositas dan Bulk & \\
\hline
\end{tabular}

Tabel 2 menunjukan bahwa dari ketiga jenis tanaman yang diamati, nilai C-organik berkorelasi postif dengan N-total yaitu sebesar $0.8420,0.839$ dan.943. Korelasi yang sangat erat ini menunjukan bahwa nisbah $\mathrm{C} / \mathrm{N}$ cenderung konstan di dalam tanah dan adanya Corganik sebagai refleksi bahan organik sebagai sumber utama N di dalam tanah (Brady, 1974 dalam Wibowo, 2006). Peubah porositas dan bulk density juga menunjukan keeratan yang cukup tinggi untuk ketiga jenis tanaman. Porositas dan bulk density memilliki korelasi negatif yaitu bertutut-turut $-0.999,-1$ dan -1 .

Pasangan peubah bebas yang memiliki nilai koefisien yang lebih dari 0.7 , akan dipilih salah satu yang dipakai dalam regresi linier berganda antara pertumbuhan ketiga jenis tanaman yang diamati dan sifat fisik dan kimia tanah. Hal ini bertujuan untuk menghindari terjadinya kolineritas dalam regresi. Peubah bebas yang dipakai yaitu C-organik, P-tersedia, Pasir, Liat dan bulk density. Hasil uji kolineritas yang diperoleh tersebut kemudian dianalisis dengan regresi linier berganda untuk melihat apakah tiap jenis tanaman memiliki kecenderungan terhadap sifat-sifat tanah tertentu. Untuk melihat seberapa besar pengaruh sifat-sifat tanah terhadap pertumbuhan tanaman, maka dilakukan uji regresi linier berganda.

\subsection{Hubungan antara pertumbuhan Shorea dengan sifat-sifat tanah}

Hubungan analisis regresi linier berganda antara peubah $\mathrm{Y}=$ riap diameter/tinggi tanaman dengan peubah X antara lain C-organik, P-tersedia, Pasir, Liat dan bulk density, dengan menggunakan $\alpha=0.05$. Analisis tersebut menghasilkan model regresi linier berganda yang disajikan pada Tabel 3 .

Hasil analisis regresi berganda menunjukan bahwa sifat fisik dan kimia tanah berpengaruh nyata pada pertumbuhan diameter dan tinggi $S$. palembanica. Hal tersebut menunjukkan bahwa C-organik, P-tersedia, bulk density, pasir dan liat secara bersama-sama memengaruhi pertumbuhan $S$. palembanica. Pada jenis $S$. leprosula dan $S$. mecisopteryx menunjukkan bahwa sifat-sifat tanah secara bersama-sama tidak memengaruhi pertumbuhan tanaman. Untuk mengetahui faktor pembatas dari sifat-sifat tanah yang paling mempengaruhi pertumbuhan masing-masing tanaman, maka dilakukan pemilihan model terbaik dengan metode stepwise. Hasil stepwise terhadap sifatsifat tanah disajikan pada Tabel 4.

Hasil regresi stepwise tersebut menunjukkan bahwa sifat tanah yang mempengaruhi pertumbuhan diameter S. leprosula adalah kadar P-tersedia (model 1). Model tersebut menunjukkan bahwa P-tersedia berpengaruh terhadap diameter dengan nilai R2 adjusted sebesar $38 \%$ dan sisanya dipengaruhi oleh peubah-peubah lain yang tidak tercakup dalam model. Kenaikan satu satuan pada peubah P-tersedia maka hal ini akan cenderung diikuti dengan kenaikan riap diameter sebesar 0.27 satuan. Pada riap tinggi, tidak ada sifat fisik dan kimia tanah yang berpengaruh secara signifikan. Sama halnya dengan riap tinggi S. leprosula, riap diameter $\mathrm{S}$. mecisopteryx tidak dipengaruhi secara signifikan oleh sifat fisik dan sifat kimia tanah. Sehingga model regresi untuk riap tinggi S. leprosula dan riap diameter $\mathrm{S}$. mecisopteryx tidak muncul. 
Tabel 3. Hasil analisis regresi linier berganda

\begin{tabular}{|c|c|c|c|c|}
\hline Jenis Tanaman & Model & $\mathrm{R}^{2}$ & $\mathrm{R}^{2}$ adj & $\mathrm{P}$-value \\
\hline \multirow{2}{*}{$\begin{array}{l}\text { Shorea } \\
\text { leprosula }\end{array}$} & $\mathrm{Yd}=7.192-0.511 \mathrm{Corg}+0.359 \mathrm{P}-0.4370 \mathrm{Bd}+0.02$ pasir -0.108 liat & 0.715 & 0.240 & 0.391 \\
\hline & $\mathrm{Yt}=4.563+0.055 \operatorname{Corg}+0.194 \mathrm{P}-2.382 \mathrm{Bd}-0.013$ pasir -0.071 liat & 0.634 & 0.023 & 0.522 \\
\hline \multirow[t]{2}{*}{$\begin{array}{l}\text { Shorea } \\
\text { mecisoPyx }\end{array}$} & $\begin{array}{l}\mathrm{Yd}=-14.890+0.161 \text { Corg }-0.309 \mathrm{P}+1.635 \mathrm{Bd}+0.204 \text { pasir }+0.329 \\
\text { liat }\end{array}$ & 0.748 & 0.329 & 0.336 \\
\hline & $\begin{array}{l}\mathrm{Yt}=-0.315-0.077 \text { Corg }-0.419 \mathrm{P}+0.814 \mathrm{Bd}+0.105 \text { pasir }+0.123 \\
\text { liat }\end{array}$ & 0.622 & -0.009 & 0.540 \\
\hline \multirow[t]{2}{*}{$\begin{array}{l}\text { Shorea } \\
\text { Palembanica }\end{array}$} & $\begin{array}{c}\mathrm{Yd}=-1.109+0.551 \text { Corg }-0.100 \mathrm{P}-0.676 \mathrm{Bd}+0.030 \text { pasir }+0.040 \\
\text { liat }\end{array}$ & 0.997 & 0.992 & $0.001 * *$ \\
\hline & $\begin{array}{c}\mathrm{Yt}=-1.786+0.526 \text { Corg }-0.089 \mathrm{P}+0.027 \mathrm{Bd}+0.005 \text { pasir }+0.048 \\
\text { liat }\end{array}$ & 0.973 & 0.929 & $0.014 *$ \\
\hline
\end{tabular}

*nyata $\mathrm{p}<0.05 * *$ sangat nyata $\mathrm{p}$ value $<0.01$

Tabel 4. Hasil stepwise

\begin{tabular}{|c|c|c|c|c|}
\hline Jenis Tanaman & Nomor & Model & $\mathrm{R}^{2}$ & $\mathrm{R}^{2}$ adjusted \\
\hline \multirow[t]{2}{*}{ S. leprosula } & 1 & $\mathrm{Yd}=-1.835+0.27 \mathrm{P}$ & 0.45 & 0.38 \\
\hline & 2 & tn & - & - \\
\hline \multirow[t]{2}{*}{ S. mecisopteryx } & 3 & tn & - & - \\
\hline & 4 & $\mathrm{Yt}=2.560-0.125 \mathrm{P}$ & 0.533 & 0.467 \\
\hline \multirow[t]{2}{*}{ S. palembanica } & 5 & $\mathrm{Yd}=-0.7301-0.151 \mathrm{P}+0.64 \mathrm{C}$-organik +0.036 Liat & 0.966 & 0.946 \\
\hline & 6 & $\mathrm{Yt}=2.399-0.142 \mathrm{P}$ & 0.715 & 0.674 \\
\hline
\end{tabular}

P-tersedia tidak hanya berpengaruh terhadap riap diameter $S$. leprosula tetapi juga memberikan pengaruh yang cukup signifikan pada riap tinggi $S$. mecisopteryx dan riap tinggi $S$. palembanica. Penurunaan satu satuan P-tersedia akan meningkatkan nilai riap sebesar 0.125 pada riap tinggi $S$. mecisopteryx dan 0.142 pada riap tinggi $S$. palembanica. Riap diameter S. palembanica dipengaruhi oleh tiga sifat tanah yaitu P-tersedia, Corganik dan Liat. Nilai riap diameternya akan meningkat saat kenaikan kadar C-organik dan Liat satu satuan, sedangkan kenaikan P-tersedia akan mengakibatkan penurunan riap diameter. Besaran kenaikan tiap penurunan atau kenaikan salah satu peubah yang memengaruhi pertumbuhan diameter $S$. palembanica dapat dilihat pada model 5.

Hasil regresi dengan metode stepwise pada ketiga jenis menunjukkan bahwa P-tersedia merupakan sifat tanah yang paling berpengaruh terhadap pertumbuhan riap diameter ataupun tinggi tanaman ketiga jenis shorea. Hasil analisis tanah juga menunjukan bahwa kadar P-tersedia pada tempat tumbuh S. palembanica dan S.mecisopteryx tergolong sedang. Pada jenis $S$. palembanica dan $S$. mecisopteryx ada kecendrungan bahwa riap diameter maupun tinggi meningkat dengan menurunnya kadar P-tersedia. Hal ini dapat diduga disebabkan karena ketergantungan $S$. palembanica dan $S$. mecisopteryx terhadap keberadaan mikoriza. Keberadaan mikoriza menyebabkan tumbuhan lebih mampu memanfaatkan bentuk-bentuk $\mathrm{P}$ yang tidak tersedia (O'dell et al. 1993 dalam Wibowo 2006). Namun, tidak semua Shorea memiliki ketergantungan terhadap keberadaan mikoriza. Pada penelitian ini hanya $S$. palembanica dan $S$. mecisopteryx yang bergantung pada mikoriza sedangkan $S$. leprosula tidak terlalu bergantung. Pertumbuhan riap diamater $S$. leprosula meningkat sejalan dengan meningkatnya kadar $\mathrm{P}$ tersedia dalam tanah. Hal ini menunjukkan bahwa S. leprosula lebih mampu memanfaatkan kadar $\mathrm{P}$ tersedia yang ada dalam tanah.

Beberapa penelitian menunjukkan bahwa Dipterocarpaceae dapat bersimbiosis dengan ektomikoriza (Riniarti, 2009; Sovu et al., 2009; Brearley, 2012; Karmilasanti dan Maharani, 2016) Ektomikoriza merupakan simbiosis mutualisme antara akar tanaman dengan cendawan tanah Mikoriza sangat membantu dalam penyerapan unsur hara bagi tanaman, terutama unsur-unsur hara yang jumlahnya sedikit dalam tanah dan tidak mobil, seperti P. Di samping membantu peningkatan serapan hara oleh akar, mikoriza juga mempunyai beberapa manfaat lain, seperti (a) meningkatkan serapan air dan ketahanan terhadap kekeringan, (b) meningkatkan ketahanan terhadap penyakit-penyakit akar dan (c) meningkatkan toleransi tanaman terhadap keracunan unsur, suhu ekstrem dan pH rendah (Munawar, 2011). Manfaat simbiosis ektomikoriza pada Shorea di antaranya ialah memungkinkan benih Shorea dapat tumbuh pada tanah dengan kondisi nutrisi yang rendah terutama fosfat (Tenakoon et al., 2005).

Pada jenis $S$. leprosula riap diameter akan meningkat saat nilai kadar P-tersedia juga meningkat. Hal ini menunjukan bahwa jenis $S$. leprosula tidak terlalu bergantung pada keberadaan mikoriza sehingga membutuhkan kadar P-tersedia yang cukup untuk mendukung pertumbuhannya. Kenaikan P-tersedia pada tempat tumbuh $S$. leprosula akan meningkatkan pertumbuhan diameter tanaman ini. S. leprosula merupakan jenis yang memiliki riap diameter terbesar dengan kadar P-tersedia pada tempat tumbuhnya tergolong sedang hingga tinggi. Meskipun demikian, 
peningkatan kadar P-tersedia memiliki batas maksimum sesuai dengan kebutuhan tanaman. Terlalu banyak $P$ dapat menyebabkan kekurangan unsur-unsur lain yang dibutuhkan tanaman seperti, $\mathrm{Zn}, \mathrm{Fe}$, dan $\mathrm{Cu}$ (Utomo dan Islami, 1995).

Nilai $R^{2}$ adjusted terbesar terdapat pada pertumbuhan diameter dan tinggi $S$. palembanica, yaitu sebesar 0.946 dan 0.674 secara berturut-turut, sedangkan kedua jenis lainnya memiliki nilai $R^{2}$ adjusted $<0.5$. Hasil tersebut menunjukkan bahwa pertumbuhan jenis yang paling dipengaruhi oleh sifat fisik dan kimia tanah, yaitu $S$. palembanica dibandingkan kedua jenis Shorea lainnya. Hal ini menunjukkan bahwa sifat tanah kondisi tempat tumbuh perlu diperhatikan saat penggunaan jenis $S$. plembanica, seperti kadar C-organik, P-tersedia dan Liat.

C-organik merefleksikan kadar bahan organik di dalam tanah. Nisbah $\mathrm{C} / \mathrm{N}$ biasa digunakan sebagai indikator jenis dan kemudahan bahan oraganik mengalami dekomposisi. Hasil analisis tanah menunjukan nisbah $\mathrm{C} / \mathrm{N}$ tergolong rendah-sedang masing-masing jenis tanaman. Nisbah $\mathrm{C} / \mathrm{N}$ rendah berarti bahan menganndung banyak $\mathrm{N}$ dan mudah terdekomposisi, sehingga cepat memasok $\mathrm{N}$ bagi tanaman (Munawar, 2011). Bahan organik mempengaruhi sifat fisik, kimia dan biologi tanah. Munawar (2011) menjelaskan bahawa tanah yang kaya bahan diameternya mampu mengikat dan menyimpan unsur-unsur hara tanaman yang bermuatan positif atau unsur logam seperti $\mathrm{Ca}, \mathrm{Mg}$ dan $\mathrm{K}$. Asam-asam yang dihasilkan pada dekomposisi bahan organik dapat melarutkan $\mathrm{P}$ tanah dan unsur-unsur mikro kurang larut, sehingga menjadi tersedia bagi tanaman.

Peningkatan bahan organik juga secara tidak langsung meningkatkan porositas tanah melalui peningkatan aktivitas fauna tanah. Banyaknya pori-pori tanah yang terbentuk membuat proses pertukaran $\mathrm{O}_{2}$ dan $\mathrm{CO}_{2}$ dalam tanah menjadi lebih baik. Selain itu, kondisi porositas tanah yang cukup tinggi dapat menyediakan pori-pori tanah dalam menampug air sehingga kebutuhan air dalam tanah masih dapat terjaga dengaan baik.

Peningkatan kadar liat (tekstur tanah) membantu pertumbuhan tanaman dalam menyimpan air dan hara. Tanah bertekstur liat memiliki porositas relatif tinggi (60\%), tetapi sebagian besar merupakan pori berukuran kecil. Akibatnya, daya hantar air sangat lambat dan sirkulasi udara kurang lancar (Utomo dan Islami, 1995). Kenaikan diameter S. palembanica sejalan dengan kadar liat menunjukan bahwa jenis ini dapat beradaptasi dan tumbuh baik pada tanah bertekstur liat.

Unsur hara esensial yang diukur dalam penelitian ini hanya unsur $\mathrm{N}$, P, dan $\mathrm{K}$ saja sedangkan unsur-unsur hara esensial yang lain tidak diukur. Hal ini dikarenakan unsur hara penting yang sering dianggap membatasi pertumbuhan tanaman di daerah tropika adalah N, P, dan K (Sanchez 1976 dalam Wibowo 2006). Ketiga unsur esensial ( N, P, K) C-oganik, dan tekstur tanah diharapkan dapat mewakili unsur-unsur hara lain yang tidak diukur dalam penelitian dengan adanya keterkaitan unsur-unsur lainnya. Selain itu, penelitian ini hanya mengambil data pada kedalaman 0$20 \mathrm{~cm}$, dimana akar-akar pada lapisan ini lebih didominasi oleh akar-akar serabut. Pada lapisan ini umumnya kandungan bahan organik juga lebih banyak sehingga unsur hara pada lapisan ini lebih banyak tersedia bagi tanaman. Namun zona perakaran tanaman bisa jauh lebih dalam dari $20 \mathrm{~cm}$ sehingga sifat-sifat tanah lain pada kedalaman akar yang lebih besar yang tidak terukur dalam penelitian mungkin juga berperan dalam pertumbuhan meranti seperti drainase tanah, kedalaman efektif, dan sebagainya.

\section{Kesimpulan}

S. palembanica merupakan jenis yang lebih dipengaruhi oleh sifat fisik dan kimia tanah dibandingkan dengan kedua jenis lainnya. Hal ini menunjukkan bahwa sifat tanah kondisi tempat tumbuh perlu diperhatikan saat penggunaan jenis $S$. plembanica, seperti kadar C-organik, P-tersedia dan Liat. Selain itu, P-tersedia merupakan kadar tanah yang memengaruhi ketiga jenis tanaman meranti merah baik riap diameter ataupun tinggi tanaman. Adanya asosiasi mikoriza dengan tanaman Shorea diduga yang mengakibatkan P-tersedia menjadi faktor pembatas pertumbuhannya. Model terpilih dari hasil analisis stepwise menunjukkan masing-masing jenis Shorea menunjukan tren yang berbeda saat terjadi kenaikan atau penurunan P-tersedia dalam tanah. Riap tinggi pada $S$. mecisopteryx dan riap diamater dan tinggi pada $S$. pelambanica akan cenderung meningkat apabila kadar P-tersedia menurun, sedangkan S. leprosula membutuhkan peningkatan kadar P-tersedia agar pertumbuhan diamaternya meningkat. Hal ini menunjukan bahwa tiap jenis tanaman memiliki respon yang spesifik terhadap kadar sifat tanah tertentu.

\section{Daftar Pustaka}

Apannah, S., dan G. Weinland, 1996. Experience with planting Dipterocarps in Peninsular Malaysia. Dalam: Schulte A, Schone D, editor. Dipterocarp Forest Ecosystem: TowardsSustainable Management. Singapur, World Scientific Publishing.

Brearley, F. Q., 2012. Ectomychorrizal associations of the Dipterocarpaceae. Biotropica 0(0), pp. 1-12.

Hamzah, M. Z., A. Arifin, A. K. Zaidey, A. N. Azirim, I. Zahari, A. Hazandy, H. Affendy, M. E. Wasli, J. Shamshuddin, dan M. N. Muhamad, 2009. Characterctic soil nutrient statut and growth performance of palnted Dipterocarp and non-dipterocarp species on degraded forest land in Peninsular Malaysia. J. Applied Science, 9(24), pp. 4215-4223.

Heyne, K., 1987. Tumbuhan Berguna Indonesia. Jilid I dan II. Terj. Badan Libang Kehutanan. Cetakan I. Koperasi karyawan Departemen Kehutanan, Jakarta.

Karmilasanti, dan R. Maharani, 2016. Kenakeragaman jenis jamur ektomikoriza pada ekosistem hutan dipterokarpa di KHDTK Labanan, Berau, Kalimantan Timur. J Penelitian Ekosisitem Dipterokarpa, 2(2). pp. 57-66.

[KLHK] Kementerian Lingkungan Hidup dan Kehutanan, 2014. Statistik kementerian lingkungan hidup dan kehutanan 2014. Kementerian Lingkungan Hidup dan Kehutanan, Jakarta.

Kok Loong Yeong, G. Reynolds, dan J. K. Hill, 2016. Enrichment planting to improve habitat quality and conservation value of 
tropical rainforest fragments. Biodivers Conserv 25, pp. $957-$ 973

Munawar, A., 2011. Kesuburan Tanah dan Nutrisi Tanaman. IPB Press, Bogor.

Nussbaum, R., dan A. L. Hoe, 1996. Rehabilitaion of degraded sites in logged-over forest using Dipterocarps. Dalam: Schulte A Schone D, editor. Dipteroccarp Forest Ecosystem: Towards Sustainable Management. World Scientific Publishing, Singapore.

Otsamo, R. A., dan G. Adjers, 1996. Reforestration experiences with Dipterocarpa species on grassland. Dalam: Schulte A, Schone D, editor. Dipteroccarp Forest Ecosystem: Towards Sustainable Management. World Scientific Publishing, Singapore.

Pusat penelitian dan Pengembangan Hutan dan Konservasi Alam, 2005. Hutan Penelitian (HP) Haurbentes. Kehutanan Badan Penelitian dan Pengembangan Kehutanan Pusat penelitian dan Pengembangan Hutan dan Konservasi Alam, Bogor.

Riniarti, M., I. Mansur, A. S. Wulandari, dan C. Kusmana, 2010. Karakteristik akar berektomikoriza pada Shorea pinanga, Pinus merkusii dan Gnetum gnemon. J Perennial, 6(1), pp. 11-19.

Schneider, T., M. S. Ashton, F. Montagnini, dan P. P. Milan, 2013. Groth performance of sixty tree species in smallholder reforestration trials on Leyte, Philippines. J. New Forest.

Sovu, M. Tigabu, P. Savadogo, dan L. Oden Xayvongsa, 2010 Enrichment planting in a logged-over tropical mixed deciduous forest of Laos. Journal of Forestry Research 21(3), pp 273-280.
Subiakto, A., H. H., C. Rachmat dan Sakai, 2016. Choosing native tree species for establishing man-mad forest: anew perspective for sustainalbe forest managemnet in changing world. J. Biodiveristas, 17(2), pp. 620-625.

Soerianegara, I., dan R. H. M. J. Lemmens, 1994. Plant Resources of South-East Asia No. 5(1) Timber Trees: Major Commercial Timber. Pudoc Scientific Publishers, Wageningen.

Tennakoon, M. M. D., I. A. U. N. Gunatilleke, K. M. Hafeel, G. Seneviratne, C. V. S. Gunatilleke, dan P. M. S. Ashton, 2005 Ectomycorrhizal colonization and seedling growth of Shorea (Dipterocarpaceae) species in simulated shade environments of a Sri Lankan rain forest. Forest Ecology and Management. 208, pp. 399-405.

Utomo, W. H., dan T. Islami, 1995. Hubungan Tanah, Air dan Tanaman. IKIP Semarang Press, Semarang.

Wahyudi, 2011. Pertumbuhan tanaman dan tegakan tinggal pada tebang pilih tanam indonesia intensif, stidu kasus di Areal Kerja IUPHHK-HA PT Gunung Meranti Provinsi Kalimantan Tengah. Disertasi. Sekolah Pascasarjana, Institut Pertanian Bogor, Bogor

Wibowo, C., 2006. Hubungan antara keberadaan saninten (Castanopsis argentea Blume) dengan beberapaa sifat tanah: kasus di Taman Nasional Gunung Gede-Pangrango, Jawa Barat. Disertasi. Sekolah Pascasarjana, Institut Pertanian Bogor, Bogor.

Widiyatno, Soekotjo, M. Naiem, S. Purnomo, dan P. E. Setiyanto, 2014. Early performance of 23 dipterocarp species planted in logged-over rainforest. Journal of Tropical Forest Science, 26(2), pp. 259-26. 